\title{
Characteristics (abundance, type and origin) of beach litter on the Galician coast (NW Spain) from 2001 to 2010
}

\author{
Jesús Gago ${ }^{1}$, Fernando Lahuerta ${ }^{2}$, Pilar Antelo ${ }^{2}$ \\ ${ }^{1}$ Instituto Español de Oceanografía (IEO), Subida a Radio Faro, 50-52, 36390 Vigo, Spain. E-mail: jesus.gago@vi.ieo.es \\ ${ }^{2}$ Ollalomar, Calle da Tarela, 40, 36350 Nigran, Spain.
}

\begin{abstract}
Summary: In order to assess the situation of beach litter on the Galician coast (NW Spain), we conducted a seasonal series of sampling on three beaches: A Lanzada, Baldaio and O Rostro. A total of 79 surveys were conducted from 2001 to 2010 on a stretch of $100 \mathrm{~m}$ and a stretch of $1 \mathrm{~km}$. A total of 37862 beach litter items were counted and classified on the $100-\mathrm{m}$ stretch and 7845 on the $1-\mathrm{km}$ stretch. The average annual value of litter items for the $100-\mathrm{m}$ beach stretch was $1016 \pm 633$, $88 \pm 31$ and $332 \pm 183$; for the $1-\mathrm{km}$ stretch, the average value of litter items was $163 \pm 87,42 \pm 31$ and $81 \pm 38$, for A Lanzada, Baldaio and $\mathrm{O}$ Rostro beaches, respectively. The most common element found in beach litter was made of plastic, with average percent of 63,38 and 83 for A Lanzada, Baldaio and O Rostro, respectively. We found that the main source of beach litter was the fishing and aquaculture sector, with an average percent value of 23, 14 and 38 for A Lanzada, Baldaio and $\mathrm{O}$ Rostro, respectively.
\end{abstract}

Keywords: beach litter; types; sources; Galician coast; NW Iberian Peninsula.

Características de basuras (abundancia, tipo y origen) en playas de la costa gallega (2001-2010)

Resumen: Con el fin de evaluar la situación de las basuras marinas en playas de la costa de Galicia (noroeste de España) se realizó una serie de muestreos estacionales en tres playas: A Lanzada, Baldaio y O Rostro. 79 muestreos se llevaron a cabo desde 2001 hasta 2010 en tramos de playas de 100 metros y $1 \mathrm{~km} .37862$ elementos fueron contados y clasificados en el tramo de 100 metros y 7845 en los estudios de $1 \mathrm{~km}$. El valor promedio anual de basuras por cada $100 \mathrm{~m}$ de playa fue $1016 \pm 633,88 \pm 31$ y $332 \pm 183$; en los muestreos de $1 \mathrm{~km}$ de playa, el valor medio fue de $163 \pm 87,42 \pm 31$ y $81 \pm 38$, para A Lanzada, O Baldaio y Rostro, respectivamente. El elemento más común que se encuentra en la basura de la playa se compone principalmente de plástico con un porcentaje promedio de 63, 38 y 83 en A Lanzada, Baldaio y O Rostro, respectivamente. Se encontró que las principales fuentes de basura en playa son la pesca y la acuicultura, con un porcentaje promedio de 23 , 14 y 38 en A Lanzada, Baldaio y O Rostro, respectivamente.

Palabras clave: basuras en playas; tipos; fuentes; costa gallega; NO Península Ibérica

Citation/Como citar este artículo: Gago J., Lahuerta F., Antelo P. 2014. Characteristics (abundance, type and origin) of beach litter on the Galician coast (NW Spain) from 2001 to 2010. Sci. Mar. 78(1): 125-134. doi: http://dx.doi.org/10.3989/ scimar.03883.31B

Editor: M. Demestre.

Received: May 7, 2013. Accepted: October 28, 2013. Published: February 21, 2014.

Copyright: (c) 2014 CSIC. This is an open-access article distributed under the Creative Commons Attribution-Non Commercial Lisence (by-nc) Spain 3.0.

\section{INTRODUCTION}

Litter on the coastline is one of the most obvious signs of marine litter pollution (see e.g. UNEP 2009). Beached marine litter such as broken glass, medical waste, fishing line, and discarded syringes can harm beach users as well as the risks associated with the leaching of poisonous chemicals (Sheavly and Register 2007, Thompson et al. 2009). The most abundant components of beach litter are plastics (Frost and Cullen 1997, Gabrielides et al. 1991, Tudor and Williams 2001).

More indirect effects come in the form of wider social impacts, influencing coastal tourism and the local economy as a result. According to the Convention for the Protection of the Marine Environment of the North-East Atlantic (OSPAR 2009), major land-based sources in the North Atlantic region include tourism 
recreation, illegal dumping, waste disposal sites and input from rivers. Major sea-based sources are fisheries, commercial shipping, pleasure crafts and offshore installations (UNEP 2009).

Surveys of litter stranded on the coastline are a primary tool for monitoring the load of litter in the marine environment and have been used world-wide to quantify and describe marine litter pollution (see e.g. Ribic et al. 2010). They can be used to measure the effectiveness of management or mitigation measures, identify the sources and activities leading to litter pollution and determine threats to marine biota and ecosystems (Martinez-Ribes et al. 2007, Cheshire et al. 2009). A number of studies have quantified beach litter and defined its components (see e.g. Ariza et al. 2008).

Monitoring programs that address clear questions are an effective way to gather information that can fruitfully be integrated with research and adaptive management (Lovett et al. 2007), as in the case of beach litter. The coming into effect of the European Marine Strategy Framework Directive (MSFD; Directive 2008/56/EC) will propel member states to create mechanisms for the management of marine litter, in order to achieve the goals established in the regulation. This is the first time that beach litter has been specifically addressed in an integrated way for the protection of the marine environment in a European directive. As pointed out by Galgani et al. (2010), the overriding objective of the MSFD on beach litter would be "a measurable and significant decrease in the total amount of litter by 2020 ".

In order to study beach litter on the Galician coast (NW Spain), three beaches were sampled from 2001 to 2010. The Galician coast has a length of over 1200 $\mathrm{km}$, of which $820 \mathrm{~km}$ correspond to cliffs and $278 \mathrm{~km}$ to Galicia's 723 beaches. The three beaches studied (A
Lanzada, Baldaio and O Rostro) are wide, gently sloping sandy beaches in dune areas exposed to the open sea, located close to major shipping lanes and fishing harbours but not close to urban areas, river mouths or sewage outfalls.

In this paper, beach litter data were analyzed in order to 1) characterize the main elements, 2) search for significant seasonal patterns and 3) determine the main sources of litter on the Galician coast. This work may also be helpful for studying local/regional factors of beach litter management on North Atlantic beaches. To our knowledge, this is the first time that data on beach litter have been studied in the Galician region.

\section{MATERIALS AND METHODS}

A major issue in producing and using data series is to assure their continuity, quality and accuracy, in order to provide good and homogeneous data sets. In practice, this factor is far from trivial. Despite the efforts in the region by municipal authorities, NGO's and other bodies to clean up beaches, the majority of these actions are made without a detailed data register or a standardised protocol.

The monitoring methodology developed during the pilot project on marine litter of the OSPAR convention (www.ospar.org) was used throughout the sampling period in our study to ensure the homogeneity of the data base. The beaches were selected according to the agreed guidelines and protocols on the OSPAR pilot project (OSPAR 2007). The beaches should be:

- composed of sand or gravel and exposed to the sea

- visually and/or frequently littered (large marine items)

- accessible for ease of marine litter removal

- over $1 \mathrm{~km}$ in length

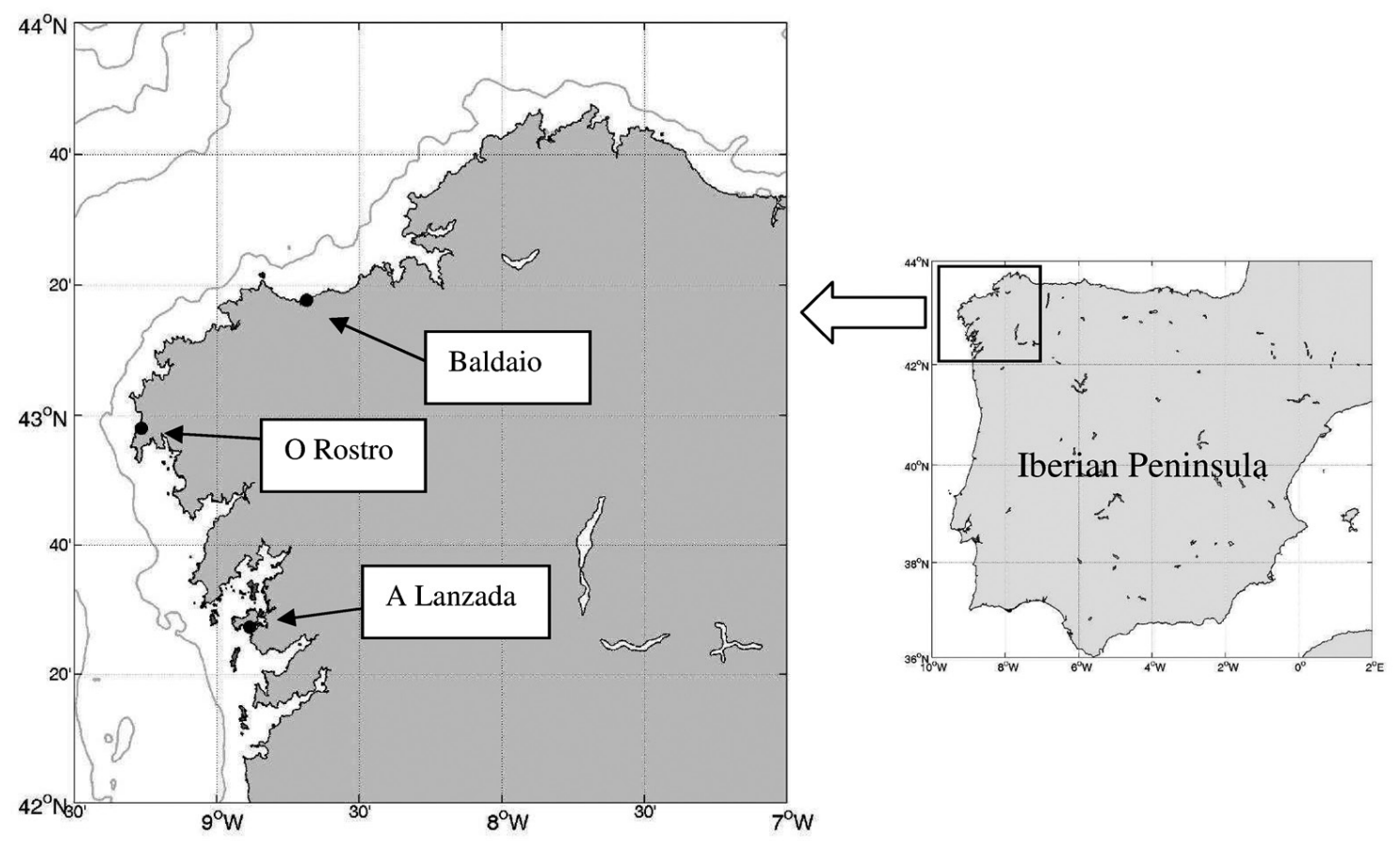

Fig. 1. - Map of the Galician coast showing the location of the three beaches. 
- not located near other input sources of waste, such as rivers

- already included in national marine beach litter activities

In addition, in order to comply with the requirements of the MSFD, which was transposed in 2010 to the Spanish national law (Law 41/2010 on the protection of the marine environment), the sampling on the beaches continued during the years 2007 to 2010 using the monitoring methodology developed within the OSPAR pilot project. One more beach (O Rostro; see Fig. 1) was also sampled in the region during this period.

\section{Beach characteristics}

A Lanzada is a great sandy long-shore tombola beach. The beach is located in an area with over 29000 inhabitants (475 inhabitants $/ \mathrm{km}^{2}$ ) spread over the territory. The largest population concentrations are in O Grove and Sanxenxo (with over 5500 and 5000 inhabitants, respectively). This area is an important tourist resort and during summer the population is over 100000 inhabitants. There are three marinas (Pedras Negras, Meloxo and $\mathrm{O}$ Grove) and a medium-size fishing port (O Grove) with over 150 vessels, mainly supporting the important mussel aquaculture industry in this region. This beach is cleaned during the summer season on a daily basis by mechanical methods.

Baldaio is a beach surmounted by low dunes. The largest nearby town is Carballo, with a population of over 30000 (160 inhabitants $\left./ \mathrm{km}^{2}\right)$. This area is a tourist resort but there is no great increase in population in summer. The beach is usually cleaned mechanically every week during the tourist season (June-August).

$\mathrm{O}$ Rostro is a large, sandy long-shore beach located in a sparsely populated area with about 6800 inhabitants spread over $35 \mathrm{~km}^{2}$ and no inhabitants nearby. The largest town is Fisterra (over 3000 inhabitants), where there is an artisanal fishing port with around 27 fishing vessels and a small marina with 30 mooring points. This area is a tourist destination but there is no great increase in population in summer. The beach is usually cleaned manually once before the summer tourist season (June-August).

The principal characteristics of the studied beaches are shown in Table 1 (for more details, see e.g. Junoy et al. 2005). All these beaches are located close to a busy shipping lane (the Finisterre corridor). The Finisterre traffic separation scheme is located around $40 \mathrm{~km}$ of the coast and the estimated traffic density is around 45000 ships/year (Garcia Negro et al. 2007).

It is also important to mention that Galicia has a major fishing tradition and a well-developed industry. Fisheries have always been an important resource to Galicia (Caballero et al. 2008). The coastline of Galicia has 42 ports, most of them with large fishery activities (fishing, aquaculture and processing industries).

\section{Sampling methodology and data classification}

According to the criteria for monitoring on each reference beach, a 100-m-long survey section on
Table 1. - Summary table describing the locations and the principal characteristics of the beaches studied.

\begin{tabular}{lcccc}
\hline Beach & Latitude & Longitude & Width $(\mathrm{m})$ & Length $(\mathrm{m})$ \\
\hline A Lanzada & $42^{\circ} 28^{\wedge} \mathrm{N}$ & $8^{\circ} 51^{\prime} \mathrm{W}$ & 127 & 2400 \\
Baldaio & $43^{\circ} 41^{\prime} \mathrm{N}$ & $8^{\circ} 41^{\prime} \mathrm{W}$ & 163 & 3650 \\
O Rostro & $42^{\circ} 90^{\prime} \mathrm{N}$ & $9^{\circ} 12^{\prime} \mathrm{W}$ & 125 & 2070 \\
\hline
\end{tabular}

the terrestrial surface of the beach was selected and marked, using permanent reference points to ensure that the same site was monitored in subsequent surveys. The 100-m section was used for detailed surveys of marine litter washed ashore or left by people visiting the beach. Also, a 1-km-long stretch of the beach was selected for surveys of larger marine items (with a less detailed survey protocol).

All surveys studied in this work were conducted by volunteers of the NGO Ollalomar (usually 2-4 persons per survey) in accordance with the survey protocols for the 100-m stretch and the $1-\mathrm{km}$ stretch developed in the OSPAR pilot project report and annexes (OSPAR 2007). These protocols were tested, evaluated and adjusted during the spring of 2001 before they were used in the regular surveys, and were further revised twice in 2002 (OSPAR 2007). Each beach was sampled, as far as possible, four times per year (winter, spring, summer and autumn) following the standard protocol mentioned above.

The three selected beaches are cleaned regularly during the tourist season on different time scales (once, weekly or daily). The beach cleaning usually takes place at the three beaches before the summer survey.

The survey protocol for surveys on the $100-\mathrm{m}$ stretch included 107 different marine litter items of all sizes. In order to identify the composition of marine litter, the 107 items identified on the 100-m stretch survey were divided into 11 major groups of materials, or specific uses, or other characteristics:

- Plastic (48 items)

- Metal (15 items)

- Paper and cardboard (8 items)

- Wood (8 items)

- Sanitary waste (6 items)

- Cloth (6 items)

- Rubber (5 items)

- Glass (3 items)

- Pottery/ceramics (3 items)

- Medical waste (3 items)

- Faeces (2 items)

The survey protocol for surveys on thea $1-\mathrm{km}$ stretch was simpler, selecting 21 types of mainly larger marine litter items.

\section{Identification of beach litter sources}

As litter found on the coastline can originate from numerous sources, measures to combat litter pollution need to target these different origins. Monitoring of litter pollution therefore also needs to be able to estimate the input from different sources in order to implement appropriate management and mitigation measures. Sources of litter can be characterized in several ways. Some items can be attributed with a high level of confi- 
Table 2. - Source-specific indicator items (as identified in the OSPAR pilot project).

\begin{tabular}{ll}
\hline Source & Indicators \\
\hline Fisheries, including aquaculture, & $\begin{array}{l}\text { Jerry cans. Fish boxes. Fishing line. Fishing weights. Rubber gloves. Ropes, cords and nets. } \\
\text { Octopus pots. Oyster nets and mussel bags. }\end{array}$ \\
$\begin{array}{l}\text { Galley waste from shipping, fisheries and } \\
\text { offshore activities (non-operational waste) }\end{array}$ & $\begin{array}{l}\text { Cartons/tetra packs. Cleaner bottles. Spray cans. Metal food cans. Plastic gloves. Plastic } \\
\text { crates. } \\
\text { Sanitary and sewage-related waste }\end{array}$ \\
$\begin{array}{l}\text { Condoms. Cotton bud sticks. Sanitary towels/panty liners/backing strips. Tampons/tampon } \\
\text { applications. }\end{array}$ \\
$\begin{array}{l}\text { Strapping bands. Industrial packaging. Hard hats. Wooden pallets. Oil drums. Light bulb/ } \\
\text { tubes. }\end{array}$ \\
$\begin{array}{l}\text { (operational waste) } \\
\text { Tourism and recreational activities } \\
\text { containers. Glass bottles. Crisp/sweet packets and lolly sticks. }\end{array}$ \\
\hline
\end{tabular}

dence to sources such as fishing items, sewage-related debris and tourist litter.

In order to determine the source of the material we will define for our study five specific sources following the OSPAR pilot project approach (OSPAR 2007): 1) fisheries (including aquaculture), 2) galley waste from shipping, fisheries and offshore activities, 3) sanitary and sewage-related waste, 4) shipping, including offshore activities, and 5) tourism and recreational activities.

This classification will be used as a basis for the analysis of the beach data. Examples of the most important items for each source are detailed in Table 2. These use categories will provide valuable information for setting targets and reduction measures, in the MSFD for example, as they are most easily linked to measures.

It must be taken into account that sources can be categorised in different ways and that it is difficult to include some of the elements in a specific sector. For example, plastic bottles are one of the most commonly recorded item but, as demonstrated in the OSPAR pilot project, there are many different sources. According to the project (OSPAR 2007), to qualify as relevant a marine litter indicator should have certain properties and should be:

- typical for the source it represents

- common and frequent in the survey area (have a high statistical power)

- easy to identify

- easy to find (not to small or inconspicuous)

- easy to count

These indicators were chosen from the 107 items included in the survey protocol for the 100-m stretches. The indicator items represent approximately 60 percent of the total number of marine litter items found, counted and identified in the 100-m surveys done in the OSPAR pilot project (a total of 614 beach surveys all around the OSPAR region). This approach will be used only for the $100-\mathrm{m}$ stretch due to the more detailed protocol.

\section{RESULTS}

Our study covers nine years (2001-2010) of beach litter data with a frequency of four samplings per year (winter, spring, summer and autumn) at A Lanzada and Baldaio beach. In the case of O Rostro, the sampling period was only from 2007 to 2010, also with four sam- plings per year. A total of 79 surveys were conducted from 2001 to 2010: 32 at A Lanzada, 33 at Baldaio and 14 at $\mathrm{O}$ Rostro. To our knowledge, our data base is one of the oldest and largest characterizing the Galician coast.

\section{Database}

A total of 37791 individual marine litter items of all sizes were identified, counted and registered (31201, 2733 and 3857 at A Lanzada, Baldaio and O Rostro, respectively) according to the standardised survey protocol on 100-m long stretches of beach. It is noteworthy that with nearly the same number of surveys the number of items at A Lanzada was more than ten times higher than that at Baldaio.

In parallel, a total of over 7845 individual marine litter items, mainly large items, were recorded during surveys made on the 1-km-long stretches of the beaches (5249, 1039 and 1557 at A Lanzada, Baldaio and O Rostro, respectively) with the less detailed survey protocol in parallel to the $100-\mathrm{m}$ stretch survey (the same number of surveys). As observed in the 100-m stretch surveys, the number of items classified at A Lanzada was higher than the number classified at Baldaio, in this case five times higher with almost the same number of surveys.

\section{0-m stretch: quantities of marine litter}

Figure 2 shows the temporal evolution of the beach litter items ( $\mathrm{a}$ and $\mathrm{b}$ for A Lanzada and Baldaio, respectively). At A Lanzada the highest values were observed in autumn, with an average value of $1785 \pm 1808$ beach litter items (BLI), and high values were also observed in winter (see Fig. 2A). On the other hand, during spring and summer the values are quite stable and similar; $253 \pm 161$ and $356 \pm 168 \mathrm{BLI}$ in spring and summer, respectively. A significant pattern of increase in winter and autumn is confirmed by linear regression analysis $\left(\mathrm{r}^{2}\right.$ and $\mathrm{p}$ of $0.32, \mathrm{p}<0.12$ and $0.35, \mathrm{p}<0.10$, for winter and autumn, respectively). The average annual value for A Lanzada is $1016 \pm 633 \mathrm{BLI}$ and there is a significant trend in increase of 159 items per year $\left(\mathrm{r}^{2}=0.47, \mathrm{p}<0.05\right)$

At Baldaio the values are very stable throughout the year and significantly lower than at A Lanzada, The lowest values are found in autumn, with an average annual value of $74 \pm 44 \mathrm{BLI}$ and the highest in 

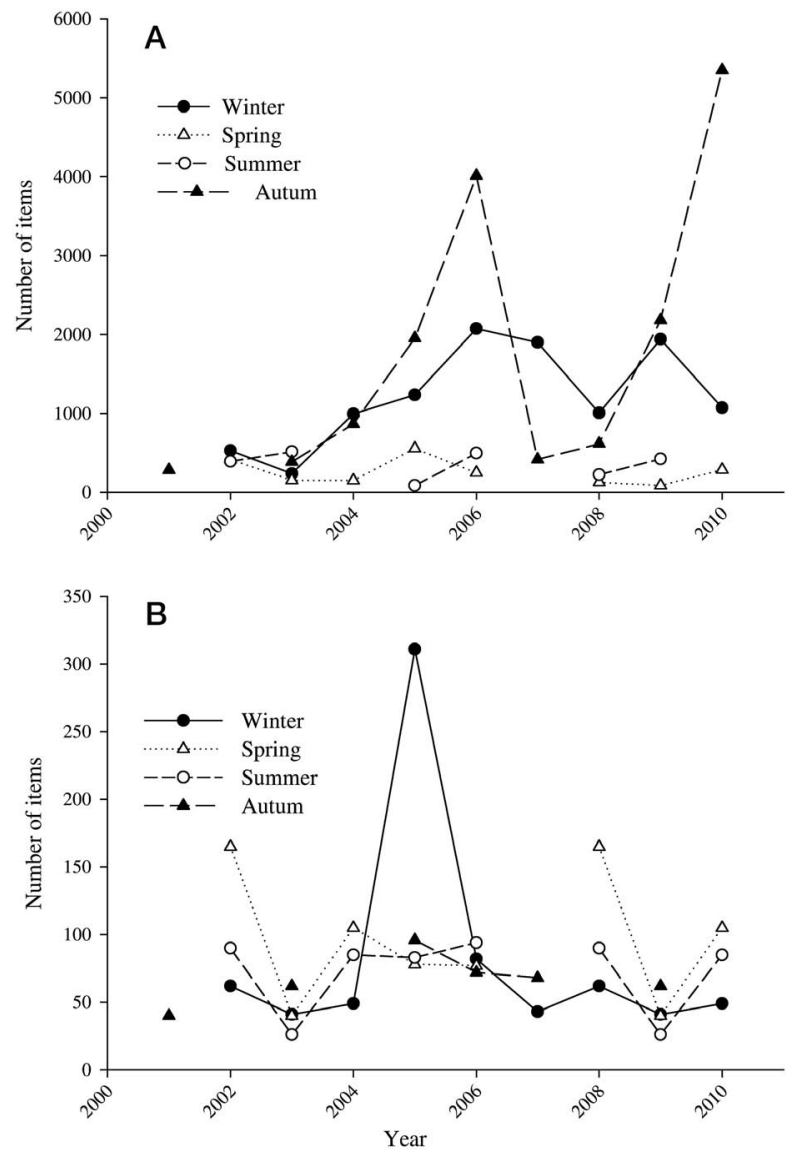

Fig. 2. - Beach litter items found during 100-m stretch surveys on A Lanzada (A) and Baldaio (B).

spring of $100 \pm 46$ BLI. In winter and summer values of $86 \pm 86$ and $81 \pm 35 \mathrm{BLI}$, were recorded respectively, and the evolution of the number of beach litter items during this seasons was quite similar, as can be seen in Figure 2B. The average annual value of beach litter items was $88 \pm 31$, nearly ten times lower than at A Lanzada. There were no significant temporal trends in this beach.

At O Rostro beach (not represented due to the lower number of surveys) the dynamics were similar to those mentioned above for the other beaches, with the highest average value in winter of $451 \pm 202 \mathrm{BLI}$. The lowest values were observed during the summer surveys, with an average value of $192 \pm 90 \mathrm{BLI}$. In spring and autumn the values were $294 \pm 8143$ and $214 \pm 65 \mathrm{BLI}$, respectively. The average annual value was $332 \pm 183$ BLI. We must take into account that $\mathrm{O}$ Rostro beach was sampled only during three years (2007-2010), so the trends cannot be compared with those of the other beaches with nearly ten years of surveys.

\section{1-km surveys of marine litter: quantities of marine litter}

In the $1-\mathrm{km}$ surveys, as expected, the numbers of marine litter items was lower. As in the 100-m surveys the highest values were observed at A Lanzada, followed by $\mathrm{O}$ Rostro and Baldaio, and the values were

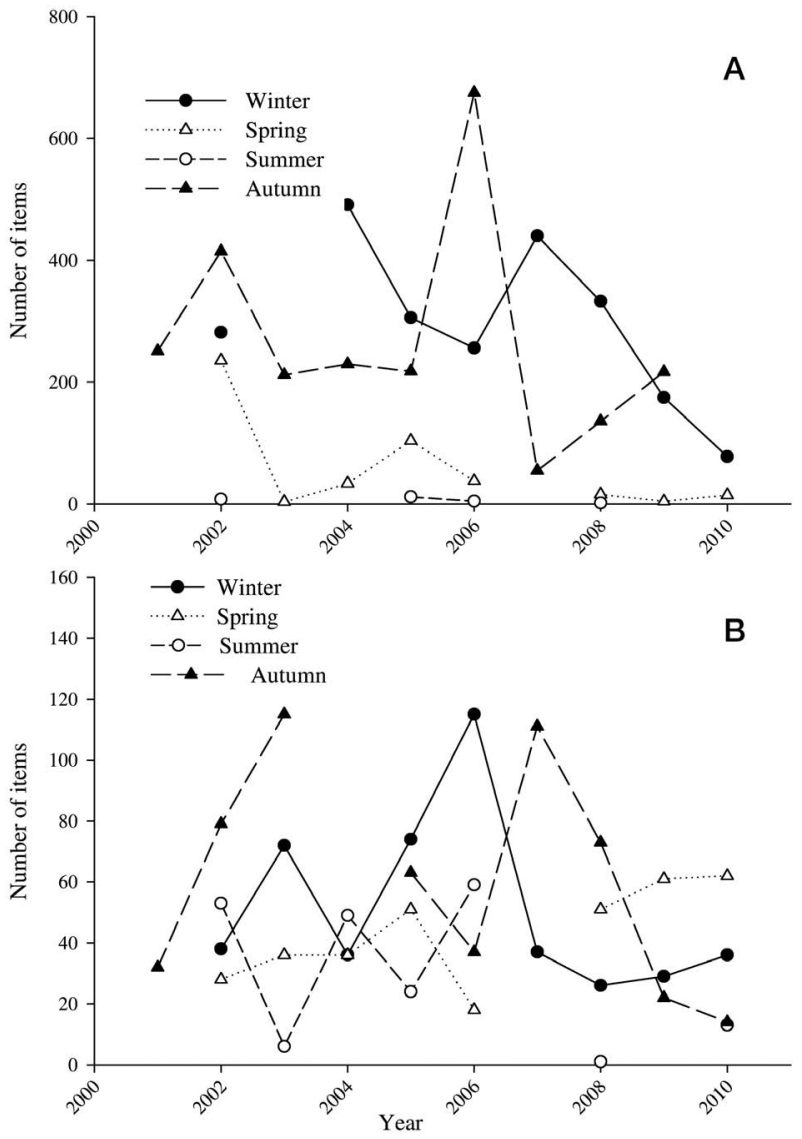

Fig. 3. - Beach litter items found during 1-km stretch surveys on A Lanzada (A) and Baldaio (B).

more similar between the three beaches. Figure 3 shows the values for A Lanzada and Baldaio (3A and $\mathrm{B}$, respectively).

At A Lanzada the values in the spring-summer surveys were lower than those in the autumn-winter surveys (as observed in Fig. 3A), as was observed in the 100-m stretch surveys. The average values were $295 \pm 133,57 \pm 79,7 \pm 4$ and $268 \pm 180$ BLI for winter, spring, summer and autumn, respectively. The average annual value of beach litter items was $163 \pm 87$ for the $1-\mathrm{km}$ stretch.

In terms of the seasonal evolution, at Baldaio beach the values were quite similar during all the seasons (see Fig. 3B), with an average annual value of $42 \pm 31$ BLI for the 1-km survey.

Finally, at $\mathrm{O}$ Rostro the seasonal dynamics were similar to those at Baldaio and the average values were $90 \pm 54,79 \pm 57,59 \pm 39$ and $89 \pm 30$ BLI for winter, spring, summer and autumn, respectively. The average annual value at this beach was $81 \pm 38 \mathrm{BLI}$ for the $1-\mathrm{km}$ stretch.

The highest values were observed at all the beaches during the winter/autumn surveys. The lowest values at the three beaches were found in summer (possibly reflecting the effectiveness of beach cleanup activities, especially with larger items as expected). The lowest average value was observed for A Lanzada during this season: $7 \pm 4$ BLI. It must be taken into account that this beach is cleaned on a daily basis during the summer. 


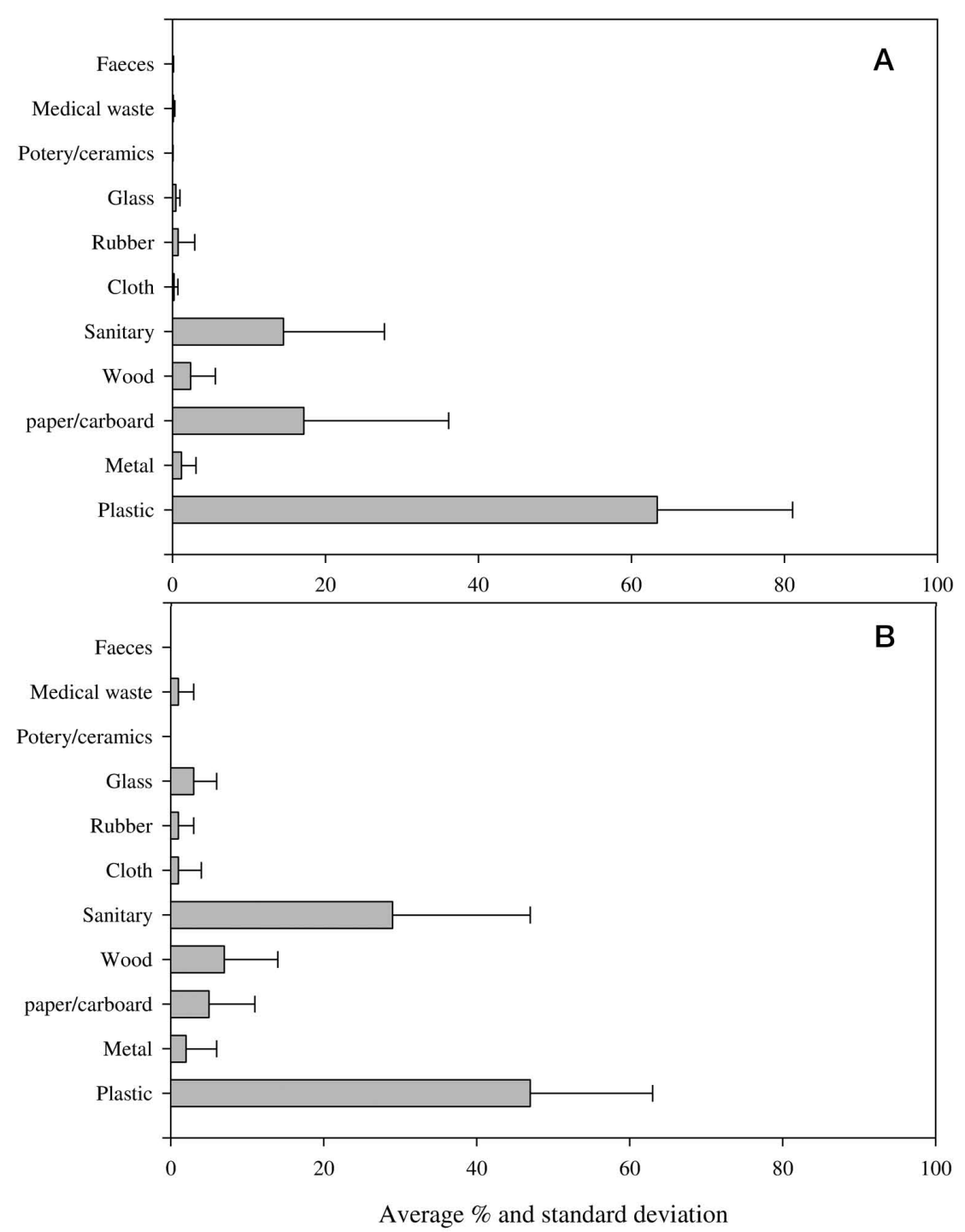

Fig. 4. - Beach litter type average percentage and standard deviation during 100-m stretch surveys for A Lanzada (A) and Baldaio (B).

\section{Beach litter composition (types)}

As defined in the material and methods part, the different items found on the 100-m section of beaches were grouped into 11 categories. Figure 4 represents the average per-centages (and standard deviation) of the surveys for A Lanzada and Baldaio beaches (4A and $\mathrm{B}$ respectively).

At A Lanzada, the three most important groups were plastic, paper/cardboard and sanitary, with average values of $63 \%, 17 \%$ and $14 \%$, respectively. Therefore, these three groups represent $94 \%$ of the total on average.

At Baldaio beach, the most important group was also plastic but with a lower value, 38\% and then sanitary and wood with $28 \%$ and $7 \%$, respectively. Unlike at A Lanzada, at Baldaio there were six groups representing nearly $95 \%$ of the total (see Fig. 4B).

At O Rostro beach, plastic was also the most important group (data not shown), with an average value of $83 \%$, the highest value. The second most important group was sanitary and the third one was metal, with $8 \%$ and $4 \%$, respectively. There were three groups with an average value of 2\%: paper/cardboard, wood and glass. As stated above, we did not use the source classification in the 1-km stretch beach surveys.

\section{Sources of beach litter}

In order to be able to set operational targets, the important source categories in the region or sub-region must first be identified. Attempts have been made to identify general indicators of sources for marine litter (see e.g. Ribic et al. 1998). It should be stressed that though this is not a rigorous method, and some items could be generated by different sectors, as stated above, it was selected by participants in the OSPAR pilot project on the basis of the findings of other projects.

According to the methodology described in the material and methods part (identification of beach litter sources), we chose five different sources and one group of items for which it is very difficult to assign the source, the so-called unknown group. Figure 5 shows the average percentages of sources for A Lanzada and Baldaio beach, A and B, respectively. 

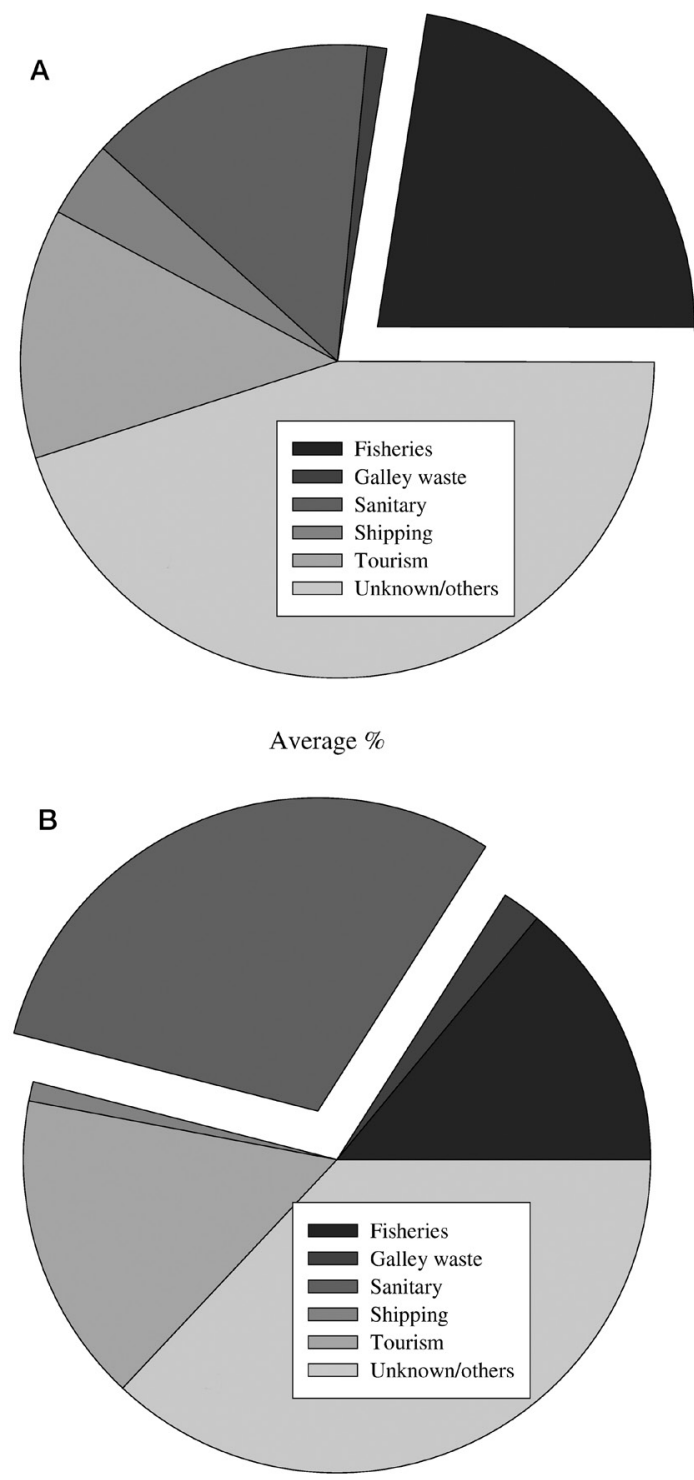

Fig. 5. - Beach litter source average percentage during 100-m stretch surveys for A Lanzada (A) and Baldaio (B).

The most important source at A Lanzada identified with our classification was fisheries, with $23 \%$. The sanitary and tourism sources were also important, with $15 \%$ and $13 \%$, respectively. Shipping and galley waste were the least important sources, with $4 \%$ and $1 \%$, respectively. We found a statistically significant increase at an annual scale in the fisheries and sanitary sectors $\left(r^{2}=0.46 ; p<0.05\right.$ and $r^{2}=0.76, p<0.005$, for fisheries and sanitary, respectively). On the other hand, shipping and tourism showed a lower contribution to beach litter $\left(\mathrm{r}^{2}=0.53 ; \mathrm{p}<0.05\right.$ and $\mathrm{r}^{2}=0.84, \mathrm{p}<0.0005$ for shipping and tourism, respectively) during the period analyzed.

At Baldaio beach, the most important source was the sanitary sector, with an average of $30 \%$. Tourism and fisheries sources contributed $16 \%$ and $14 \%$, respectively. Shipping and galley waste, as at A Lanzada, were also less important sources, with $4 \%$ and $1 \%$, respectively. At this beach, a significant trend was only found for the fisheries sector and, as at A Lanzada, we found an increase $\left(\mathrm{r}^{2}=0.35\right.$ and $\left.\mathrm{p}<0.1\right)$.
The results for $\mathrm{O}$ Rostro beach are quite similar to those for A Lanzada, with the highest value observed in fisheries, $38 \%$, followed by tourism and sanitary, $14 \%$ and $8 \%$, respectively. Shipping and galley waste were also small contributors at this beach, with $3 \%$ and $1 \%$, respectively.

It is noteworthy that in a region with a great deal of shipping traffic (the Finisterre corridor is $\sim 40 \mathrm{~km}$ from the Galician coast, with a traffic of around 45000 merchant vessels per year), shipping was a minor contributor to litter at all the beaches and we found that its contribution (using our classification) fell during the analyzed period. It must be pointed out that this could also result from the fact that some items cannot be assigned clearly to only one source and the contribution of shipping could be lower than its real value due to the fact that only floating marine litter is deposed on the coastline.

Unknown or unassigned items represented on average $46 \%, 37 \%$ and $36 \%$ of beach litter for A Lanzada, Baldaio and $\mathrm{O}$ Rostro beaches, respectively. These values are similar to that determined with all the data in the OSPAR pilot project: $40 \%$ on average for the total number of items classified with an unknown source.

\section{DISCUSSION}

Counting the number of individual beach litter items provides the easiest and cheapest information for the formulation of management measures at all levels (linking items to sources and use), as recently indicated by a marine litter group of experts (Piha et al. 2011). It is also the most practical method, though other additional methods such as assessment of the weight of the items found (Piha et al. 2011) can be valuable.

On average we found $975 \pm 1173,85 \pm 56$ and $276 \pm 151$ BLI per survey on the $100-\mathrm{m}$ stretch of beach at A Lanzada, Baldaio and O Rostro, respectively. In the OSPAR pilot project on monitoring beach litter an average of 542 items per 100 metres were counted on the reference beaches (throughout the OSPAR region). On the $1-\mathrm{km}$ stretch we found on average $181 \pm 174$, $47 \pm 29$ and $80 \pm 41$ BLI per survey at A Lanzada, Baldaio and $\mathrm{O}$ Rostro, respectively compared with the average of 67 items found in the OSPAR pilot project.

Therefore, the number of beach litter items found on the Galician coast during the 100-m stretch surveys (mainly small items) was lower than the number found in the OSPAR area, indicating that this area is less polluted with beach litter than the average (with the exception of A Lanzada, with values twice the average). On the other hand, the number of items found on the $1-\mathrm{km}$ stretch (bigger items) was quite similar to the average value and the number found at A Lanzada was nearly three times the average in the OSPAR region.

It is very difficult to compare beach litter concentrations of various coastal areas obtained from various studies with different methodologies. Nevertheless, compared with some recent studies on beach litter, the average densities on the Galician coast seem to be lower than in tourist areas of the Mediterranean (3600 BLI per 100 m; Martinez-Ribes et al. 2007), the 
Black sea (2400 BLI per 100 m; Topçu et al. 2013) and populated areas of Brazil (500 to 10000 BLI per $100 \mathrm{~m}$; Tourinho and Fililman 2011). Comparisons with other studies in the Atlantic show that our average values are very similar to those reported for England (85 BLI per $100 \mathrm{~m}$; Willoughby et al. 1997) and the US Atlantic coast (72 BLI per $100 \mathrm{~m}$; Ribic 1998) and very close to those of the North Atlantic (66 BLI per 100; Barnes and Milner 2005).

As indicated in the OSPAR pilot project, there is great variation in the number of marine litter items found on reference beaches all across the OSPAR maritime area (OSPAR 2007). The reasons for this variation lie in the source (close to river mouth or major harbours), oceanographic processes and the cleaning frequency on the beaches (beaches in the major tourist destinations are cleaned nearly on a daily basis, whereas others are cleaned only once per season or even per year). This makes comparison more difficult.

Therefore, in order to evaluate the main sources, the measures to implement and their effectiveness for reducing beach litter, a regional analysis is more valuable. The local factors (rivers, ports, beachgoers, currents,) influencing beach litter quantity and type need a specific analyses that can be masked in global analysis.

The great differences between seasons (at least in the Galician region, as demonstrated herein) suggest that the values should be compared on a seasonal basis for the same region. These differences are due to several factors, but probably mainly beach cleaning during specific periods and intensified accumulation of litter on beaches caused by oceanographic processes.

It is also important to note that beach cleaning frequency is very important to interpret the statistical analyses. If surveys are made on beaches that have not been cleaned until recently, and especially after monitoring has started, the reduction could be artificially generated by the increased frequency of cleaning.

Beach cleaning can be less of a problem for surveys if it is controlled and regular, i.e. the same intensity is maintained over time. For example, if surveys are done in each season previous to the beach cleaning, it will be possible to detect trends in beach litter quantity and composition. In our case, at A Lanzada and Baldaio beaches mechanical cleaning takes place regularly (daily and weekly, respectively) during the summer tourist season. Beach cleaning at $\mathrm{O}$ Rostro is usually manual and takes place only once per year, at the beginning of the summer season.

A remarkable fact during the sampling period in the Galician region is the well-known Prestige tanker incident (see e.g. Albaiges et al. 2006). The Prestige broke and sank close to the Galician coast (about $42^{\circ} 10^{\prime} \mathrm{N}$ and $12^{\circ} 05^{\prime} \mathrm{W}, 133 \mathrm{~nm}$ off the coast) in November 2002. Galician beaches were cleaned during the winter and spring of 2002-2003, removing the fuel and underlying sand, mainly with the aid of shovels. In May 2003, most of the Galician beaches $(98.3 \%)$ were cleaned, and cleanup activities were limited to removing tar balls that occasionally reached the beaches (Junoy et al. 2005). This incident could affect to the initial values of our study, as low values could be due to these intensive cleanup activities on the beaches. In fact, the lowest values of beach litter items in A Lanzada and Baldaio beaches in winter-autumn were observed in 2003 (see Figs 2A and B). Similar effects are expected to be observed in zones affected by incidents like this, such as the French coast after the "Erika" tanker disaster.

Plastic accounted for $63 \%, 47 \%$ and $38 \%$ of BLI at A Lanzada, Baldaio and $\mathrm{O}$ Rostro, respectively. The OSPAR survey found an average of $75 \%$ of nondegradable plastic and/or polystyrene in all the 100-m stretch surveys. Our coastal zone therefore showed a lower percentage than the OSPAR region. Similar results showing the ubiquitous presence of plastics items in the marine environment are found world-wide and indicate the predominance of plastics among marine litter (see e.g. Derraik 2002). Though the methods were not assessed to ensure that the results were comparable, the proportion varies between $32 \%$ and $88 \%$ of total beach litter (Derraik 2002).

This is a threat to humanity because plastic does not degrade but is only broken into small particles called microplastics. For example, Browne et al. (2010) found 65\% of litter sampled in Plymouth, UK, was microplastic. This is also a problem of concern in the Iberian region; a recent study (Martins and Sobral 2011) reported $72 \%$ of microplastics in litter from five beaches in Portugal.

The unknown or unassigned source items represent $46 \%, 37 \%$ and $36 \%$ of BLI at A Lanzada, Baldaio and O Rostro, respectively. These values are similar to the average value determined in the OSPAR pilot project, around $40 \%$.

It is also important to mention that in the OSPAR pilot project only beach litter items from the fishing sector showed a statistically significant increase on the sampled beaches. Our results for the Galician region (with more temporal coverage than the OSPAR pilot project) are similar: an increase in the fishing sector items on all the beaches. The fishing and aquaculture sector is very important in the Galician region. In Galicia $4.6 \%$ of the active population is employed in the fisheries sector, a much higher percentage than in any other European Union country (Vazquez Seijas 1998).

Beach litter can only provide some of the information necessary to supply a full picture of the total load of marine litter in the marine environment. Any interpretation of data on beached marine litter, as a reflection of the overall marine litter situation in a given area, should be made with this uncertainty in mind, especially referring to the section of our work on sources of beach litter. For example, only floating marine litter from shipping will reach the beaches; other elements of this litter will sink in the water column and accumulate on the seabed.

We should be cautious about a long-term interpretation of our results since we studied a period of only 10 years. Nevertheless, our study could be interesting for a larger geographical level, at least covering the Iberian upwelling system.

Finally, Tudor and Williams (2001) verified that the use of volunteers to conduct beach litter surveys is a reliable method, showing no statistical difference 
between the results of data gathered by inexperienced and experienced surveyors.

\section{CONCLUSIONS}

Beach litter monitoring programmes based on regular surveys of stretches of beaches can be particularly valuable for defining background values and determining trends. This is especially important in the case of descriptor 10 (marine litter) of the MSFD. These programmes are extraordinarily difficult to maintain and few survive for periods longer than a decade, like the national marine debris monitoring programme of the National Oceanic and Atmospheric Administration (Ribic et al. 2010). The OSPAR pilot project on monitoring beach litter has therefore been a successful pioneering European initiative that extended in time to the Galician coast because of the requirements of the MSFD.

Our work provides a baseline value for beach litter on the Galician coast referring to the year 2001 and will be very valuable for determining the effectiveness of the measures and policies aimed at reaching a good environmental status in this region by 2020 , as defined in the MSFD.

This monitoring programme on the Galician coast is expected to continue in the near future in order to evaluate the temporal evolution in beach litter on this area. It should also be stressed that this information can be used as a basis for marine management decisions and policy development, such as in the definition of operational targets in the MSFD.-

Our study confirms the importance of plastics in the marine environment, as indicated by several studies (Derraik 2002, Thompson et al. 2004). The fragmentation of plastic into small particles (not detected by the human eye) should be considered in new monitoring programmes, especially because of the slow degradability of these materials.

It is not surprising that in a region with a high dependence on fishing and aquaculture this sector represents the main source of beach litter. The contribution from the fisheries/aquaculture sector to beach litter in the studied region has increased during our sampling period. However, this does not indicate an inappropriate activity in this sector because the items are mainly lost during routine activities or during severe meteorological conditions. Nevertheless, in order to restrict litter related to the fishing and shipping industry, measures such as better schooling of fishermen are needed.

Finally, it should be pointed out that there are limited data on the overall influence that beach litter has on the environment and society, and further research is needed (UNEP 2005, Mouat et al. 2010).

\section{ACKNOWLEDGEMENTS}

This work was supported by the Spanish Ministry of the Environment as a contribution to the OSPAR pilot project on monitoring beach litter. We are very grateful to an anonymous reviewer who made a number of good suggestions to improve this paper. We ex- press our sincere thanks to the many people who have done very much for many years and made this study possible. We also thank Gonzalo Gonzalez for his help with the figures.

\section{REFERENCES}

Albaiges J., Morales-Nin B., Vilas F. 2006. The prestige oil-spill: A scientific response. Mar. Pollut. Bull. 53: 205-207. http://dx.doi.org/10.1016/j. marpolbul.2006.03.012

Ariza E., Jiménez J.A., Sardá R. 2008. Seasonal evolution of beach waste and litter during the bathing season on the Catalan coast. Waste Manag. 28: 2604-2613. http://dx.doi.org/10.1016/j.wasman.2007.11.012

Barnes D.K.A, Milner P. 2005. Drifting plastic and its consequences for sessile organism dispersal in the Atlantic Ocean. Mar. Biol. 146: 815-825. http://dx.doi.org/10.1007/s00227-004-1474-8

Browne M.A., Galloway T.S., Thompson R.C. 2010. Spatial patterns of plastic debris along estuarine shorelines. Environ. Sci. Technol. 44: 3404-3409. http://dx.doi.org/10.1021/es903784e

Caballero Miguez G., Garza Gil M.D., Varela Lafuente M. 2008. Institutions and management of fishing resources: The governance of the Galician model. Ocean Coast. Manage. 51: 625-631. http://dx.doi.org/10.1016/j.ocecoaman.2008.06.003

Cheshire A.C. and 18 co-authors. 2009. UNEP/IOC Guidelines on survey and monitoring of marine litter. UNEP Regional seas reports and studies, $\mathrm{N}^{\circ} 186$; IOC Technical series $\mathrm{n}^{\circ} 83,120 \mathrm{pp}$.

Derraik J.G.B. 2002. The pollution of the marine environment by plastic debris: a review. Mar. Pollut. Bull. 44: 842-852. http://dx.doi.org/10.1016/S0025-326X(02)00220-5

Frost A., Cullen M. 1997. Marine debris on northern New South Wales beaches (Australia): sources and the role of beach usage. Mar. Pollut. Bull. 34: 348-352. http://dx.doi.org/10.1016/S0025-326X(96)00149-X

Gabrielides G.P., Golik A., Loizides L., Marino M.G., Bingel F., Torregrosa M.V. 1991. Man-made garbage pollution on the Mediterranean coastline. Mar. Pollut. Bull. 23: 437-441. http://dx.doi.org/10.1016/0025-326X(91)90713-3

Galgani F., Fleet D., van Franeker J., Katsanevakis S., Maes T., Mouat J., Oosterbaan L., Poitou I., Hanke G., Thompson R., Amato E., Birkun A., Janssen C. 2010. Marine Strategy Framework Directive Task Group 10 Report. Marine litter. EUR 24340 EN-2010.

Garcia Negro M.C., Villasante C.S., Carballo Penela A. 2007. Compensating system for damages caused by oil spill pollution: Background for the Prestige assessment damage in Galicia, Spain. Ocean Coast. Manage. 50: 57-66. http://dx.doi.org/10.1016/j.ocecoaman.2006.08.014

Junoy J., Castellanos C., Vieitez J.M., De la Huz M.R., Lastra M. 2005. The macroinfauna of the Galician sandy beaches (NW Spain) affected by the Prestige oil-spill. Mar. Pollut. Bull. 50: 526-536. http://dx.doi.org/10.1016/j.marpolbul.2004.11.044

Lovett G.M., Burns D.A., Driscoll C.T., Jenkins J.C., Mitchell M.J., Rustad L., Shanley J.B., Likens G.E., Haeuber R. 2007. Who needs environmental monitoring? Fron. Ecol. Env. 5: 253-260. http://dx.doi.org/10.1890/1540-9295(2007)5[253:WNEM] 2.0.CO;2

Martinez-Ribes L., Basterretxea G., Palmer M., Tintore J. 2007. Origin and abundance of beach debris in the Balearic Islands. Sci. Mar. 71(2): 305-314. http://dx.doi.org/10.3989/scimar.2007.71n2305

Martins J., Sobral P. 2011. Plastic marine debris on the Portuguese coastline: A matter of size? Mar. Pollut. Bull. 62: 2649-2653. http://dx.doi.org/10.1016/j.marpolbul.2011.09.028

Mouat J., Lozano R.L., Bateson H. 2010. Economic Impacts of Marine Litter. Kommunenes Internasjonale Miljøorganisasjon (KIMO), Grantfield (UK), 105 pp.

OSPAR. 2007. Monitoring of Marine litter in the OSPAR Region. Publication No. 306/2007. ISBN 978-1-905859-45-0. London, United Kingdom, 74 pp.

OSPAR. 2009. Marine litter in the North-East Atlantic Region: Assessment and priorities for response. Publication No. 386/2009. ISBN 978-1-906840-26-6. London, United Kingdom, 120 pp.

Piha H.E., and 25 co-authors. 2011. Marine litter: Technical recommendations for the implementation of MSFD requirements. ISBN 978-92-79-21801-9, Luxembourg, $91 \mathrm{pp}$.

Ribic C.A. 1998. Use of indicator items to monitor marine debris on a New Jersey beach from 1991 to 1996. Mar. Pollut. Bull. 36: 
887-891. http://dx.doi.org/10.1016/S0025-326X(98)00064-2

Ribic C.A., Sheavly S.B., Rugg D.J., Erdman E.S. 2010. Trends and drivers of marine debris on the Atlantic coast of the United States. Mar. Pollut. Bull. 60: 1231-1242.

http://dx doi.org/10.1016/ j.marpolbul.2010.03.021

Sheavly S.B, Register K.M. 2007. Marine Debris and Plastics: Environmental Concerns, Sources, Impacts and Solutions. J. Poly. Env. 15:301-305. http://dx.doi.org/10.1007/s10924-007-0074-3

Thompson R.C., Olsen Y., Mitchell R.P., Davis A., Rowland S.J., John A.W.G., McGonigle D., Russell A.E. 2004. Lost at sea: where is all the plastic? Science 304: 838. http://dx.doi.org/10.1126/science.1094559

Thompson R.C., Moore C.J., von Saal F.S., Swan S.H. 2009. Plastics, the environment and human health: current consensus and future trends. Philos. Trans. R. Soc. Lond. B 364: 2153-2166. http://dx.doi.org/10.1098/rstb.2009.0053

Topçu E.N., Tonay A.M., Dede A., Öztürk A.A., Öztürk B. 2013. Origin and abundance of marine litter along sandy beaches of the Turkish Western Black Sea Coast. Mar. Env. Res. 85: 21-28. http://dx.doi.org/10.1016/j.marenvres.2012.12.006

Tourinho P.S., Fillmann G. 2011. Temporal trend of litter contamination at Cassino beach, Southern Brazil. J. Integ. Coast. Zone Manage. 11(1): 97-102.

Tudor D.T., Williams A. 2001. Investigation of litter problems in the Severn Estuary/Bristol Channel area. R \& D Technical Summary E1-082/TS. Environment Agency, Bristol, U.K.

UNEP 2005. Marine Litter: An analytical overview. UNEP, Nairobi, Kenya.

UNEP 2009. Marine Litter: A global challenge. UNEP, Nairobi, Kenya.

Vazquez Seijas V. 1998. The future for fisheries-dependent communities: the fisheries-dependent region of Galicia. J. Northw. Atl. Fish. Sci. 23: 175-184. http://dx.doi.org/10.2960/J.v23.a11

Willoughby N.G., Sangkoyo H., Lakaresu B.O. 1997. Beach litter: an increasing and changing problem for Indonesia. Mar. Pollut. Bull. 60: 1231-1242. 